\title{
ANALISIS MODULUS ELASTISITAS DAN KUAT TARIK PADA POLYMER MODIFIED MORTAR (PMM) DENGAN PENAMBAHAN SERAT CANTULA (AGAVE CANTULA ROXB)
}

\author{
"Modulus of Elasticity Analysis and Tensile Strength of Polymer Modified Mortar (PMM) with \\ Addition of Cantula Fiber (Agave Cantula Roxb)"
}

\author{
Firman Pratama ${ }^{1)}$, Edy Purwanto ${ }^{2)}$, Stefanus Adi Kristiawan ${ }^{3)}$ \\ 1) Mahasiswa Program Studi Teknik Sipil, Universitas Sebelas Maret \\ 2) 3)Pengajar Program Studi Teknik Sipil, Universitas Sebelas Maret \\ Jln Ir Sutami 36 A, Surakarta 57126 \\ e-mail : mrfirmanpratama@gmail.com
}

\begin{abstract}
The combination of building materials and textile technology in modern times continues to increase, so as to form textile reinforced concrete. Where the use of textile reinforced concrete can help bridges, pillars or reinforced concrete to withstand vibrations, sudden jerks and torque. But basically the weakness of reinforced concrete still tends to use steel reinforcement so it is susceptible to corrosion. Alternatives to overcome this situation by using natural alternative materials, one of which is cantula fiber (Agave Cantula Roxb) which is covered with polymer modified mortar. This study discusses the effect of modulus of elasticity on matrix variations in the form of polymer modified mortar (PMM) and textile reinforced concrete $(T R C)$ by using variations of woven cantula fibers in the form of $10 \mathrm{~mm} \times 10 \mathrm{~mm}, 10 \mathrm{~mm} \times 20 \mathrm{~mm}, 10 \mathrm{~mm} \times 15 \mathrm{~mm}, 20 \mathrm{~mm} \times 10 \mathrm{~mm}$ and $15 \mathrm{~mm} \times 10 \mathrm{~mm}$ and tensile strength on polymer modified mortar (PMM). The test is done by pulling the test object directly at the age of 28 days. The results of the test showed the highest increase in tensile strength in the PMM TRC 200 specimen $(10 \mathrm{~mm} \times 20 \mathrm{~mm})$ with a tensile strength value of $1.50 \mathrm{MPa}$ at 28 days. The greatest modulus of elasticity in TRC is found in PMM TRC 200 (10 mm $20 \mathrm{~mm})$ with an elastic modulus value of 262.2968 MPa and tensile strength value of $21.3508 \mathrm{MPa}$ at 28 days.
\end{abstract}

Keywords: reinforcement ratio, textile reinforced concrete, cantula fiber.

\begin{abstract}
ABSTRAK
Kombinasi ilmu material bahan bangunan dan teknologi tekstil di zaman modern terus meningkat,shingga terbentuk textile reinforced concrete. Dimana penggunaan textile reinforced concrete dapat membantu jembatan, pilar atau beton bertulang untuk menahan getaran, sentakan tiba-tiba dan torsi. Namun pada dasarnya kelemahan reinforced concrete masih cenderung menggunakan tulangan baja sebingga rentan terbadap korosi. Alternatif untuk mengatasi keadaan tersebut dengan penggunaan bahan alternatif alam, salab satunya adalah serat cantula (Agave Cantula Roxb) yang diselimuti dengan polymer modified mortar. Penelitian ini membahas pengaruh modulus elastisitas terhadap variasi matriks yang berupa polymer modified mortar (PMM) dan textile reinforced concrete (TRC) dengan menggunakan variasi anyaman serat cantula berupa $10 \mathrm{~mm} \times 10 \mathrm{~mm}, 10 \mathrm{~mm} \times 20 \mathrm{~mm}, 10 \mathrm{~mm} \times 15 \mathrm{~mm}, 20 \mathrm{~mm} \times 10 \mathrm{~mm}$ dan $15 \mathrm{~mm} \times 10 \mathrm{~mm}$ dan kuat tarik pada polymer modified mortar (PMM). Pengujian dilakukan dengan cara tarik langsung benda uji pada umur 28 bari. Hasil dari pengujian didapatkan kenaikan tertinggi kuat tarik pada benda uji PMM TRC $200(10 \mathrm{~mm} \times 20 \mathrm{~mm})$ dengan nilai kekuatan tarik sebesar $1.50 \mathrm{MPa}$ pada umur 28 hari. Nilai modulus elastisitas terbesar pada TRC terdapat pada PMM TRC 200 (10 mm $\times 20 \mathrm{~mm})$ dengan nilai modulus elastisitas sebesar 262.2968 MPa dan nilai kuat tarik sebesar 21.3508 MPa pada umur 28 hari.
\end{abstract}

Kata kunci: reinforcement ratio, textile reinforced concrete, serat cantula.

\section{PENDAHULUAN}

Kebutuhan beton dalam pekerjaan konstruksi semakin banyak. Secara umum beton bertulang merupakan material pokok utama sebagai struktur penguat. Keunggulan karakteristik seperti durabilitas, kuat tekan dan kekakuan yang tinggi dibandingkan dengan struktur bahan yang lainnya, membuat beton diminati untuk pekerjaan konstruksi. Akan tetapi pada dasarnya beton bertulang juga masih memiliki kelemahan yaitu kuat tarik yang rendah. Selain itu tulangan pada batang baja dapat juga berkorosif, sehingga dapat mempengaruhi kualitas beton.

Textile Reinforced Mortar (TRM), atau yang juga dikenal dalam literatur internasional sebagai Textile Reinforced Concrete (TRC) merupakan salah satu inovasi untuk memperkuat beton bertulang. Textile Reinforced Concrete terdiri dari tekstil, yaitu jerat kain yang terbuat dari anyaman, rajutan atau tenunan setidaknya dua arah yang diresapi dengan pengikat berupa mortar (Triantafillou dkk, 2007).

Pada textile reinforcement sering digunakan berupa material non-nature,yang berupa serat kaca tahan alkali (AR), aramid, basalt dan carbon fabrics. Oleh karena itu penelitian mencari solusi alternatif untuk reinforcement berbasis nature. Pada penelitian Raharjo (2015) menyatakan bahwa serat Agave Cantula Roxb merupakan serat alam yang memiliki kemampuan mekanik yang tinggi. Hasil survey dari Badan Penilitian dan Pengembangan Industri 
Departemen Perindustrian Yogyakarta, menyatakan bahwa cantula mempunyai kandungan selulose 64,3\% sehingga serat ini berpotensi sebagai bahan penguat komposit (Raharjo dkk., 2015). Kelebihan yang dimiliki oleh serat cantula itu sendiri diantaranya yaitu harga murah, dapat diuraikan oleh alam, mudah di dapat (producible), kuat, ringan dan kemampuan mekanik yang tinggi (Kurniawan Indra P, Wijang Wisnu Raharjo, 2015).

\section{TINJAUAN PUSTAKA}

Karakteristik Textile Reinforced Concrete (TRC)

Pada dasarnya Textile Reinforced Concrete (TRC) berupa komposit yang terdiri dari tekstil dan polymer modified mortar yang berfungsi sebagai reinforcement dan beton digunakan sebagai matriks. Reinforcement pada tekstil memberikan dukungan dalam memperkuat struktur beton yang ada di dalam dengan memberikan dukungan kuat lentur, penambahan kekuatan penahan, dan tegangan geser.

Efek dari TRC sebagai perkuatan telah berhasil dibuktikan oleh beberapa proyek penelitian. Namun, penerapannya untuk sebagai teknisasi bahan dasar masih perlu banyak penyelidikan. Satu langkah penting untuk mencapai tujuan ini adalah dengan memodelkan perilaku mekanik TRC untuk aplikasi numerik ke dalam situasi nya.

\section{Karakteristik Polymer Modified Mortar (PMM)}

Polymer modified mortar merupakan kombinasi dari mortar dengan polymer, dalam penelitian ini polymer yang digunakan adalah polyvinyl acetate. Dalam beton terjadi reaksi pengikatan yang terjadi oeleh reaksi hidrasi semen dan polimerisasi yang berasal dari polyvinyl acetate dalam beton. Dalam proses pengikatan semen dan pembentukan matrix polimer semen ada tiga tahapan, yaitu,

a) Ketika polimer dicampur dengan semen segar atau beton, partikel polimer tersebar merata dalam fase pasta semen.

b) Kerna perkembangan struktur gel semen, partikel polimer secara bertahap mengisi pori - pori kapiler. Efek dari ikatan kimia cendrung untuk di imbangi dengan meningkatkan entraining air.

c) Pada akhirnya, air yang menguap karena hidrasi semen, polimer pada semen menyatu menjadi membran.

(a) Immediately after

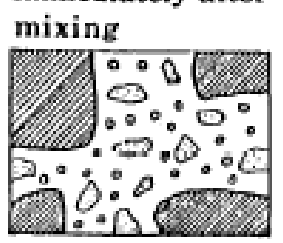

Utis Unhydrated cement particles

- Polymer particles

Aggregates

(b) First step

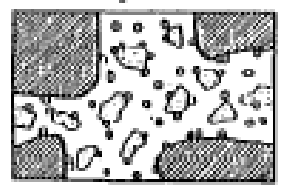

(c) Second step

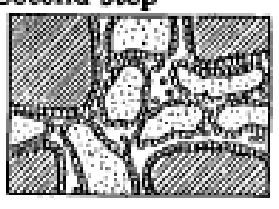

(d) Third step

(Hardened structure)

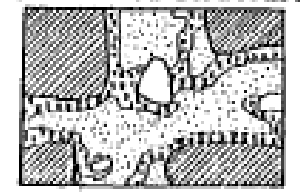

(Interstitial spaces are water)

ชo Mixtures of unhydrated cement particles and cement gel

(On which polymer particles deposit partially)

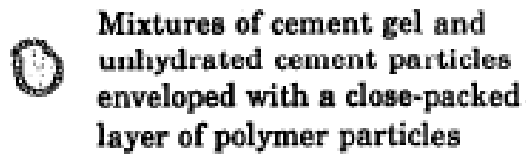

Cement hydrates enveloped

with polymer films or memberanes

$0^{5}$ Entrained air

Gambar 1. Ilustrasi tahapan pengikatan polimer dan semen PMM

\section{Kuat Tarik Langsung}

Uji tarik adalah suatu uji yang menunjukkan bagaimana benda uji bereaksi terhadap gaya tarik dan sejuah mana deformasi dari bahan tersebut. Uji kuat tarik langsung merupakan pengujian dimana beton diberi gaya aksial 
hingga beton runtuh.Besarnya nilai kuat tarik langsung mortar pada benda uji digunakan persamaan 1 sebagai berikut.

$$
\mathrm{f}^{\prime} \mathrm{C}=\frac{P_{\text {maks }}}{A}
$$

dimana :

$\mathrm{f}^{\prime} \mathrm{c} \quad=$ Kuat tekan mortar $(\mathrm{MPa})$

$\mathrm{P}_{\text {maks }}=$ Beban tekan maksimum $(\mathrm{N})$

$\mathrm{A} \quad=$ Luas permukaan benda uji $\left(\mathrm{mm}^{2}\right)$

\section{Modulus Elastisitas}

Tolak ukur yang umum dari sifat elastis suatu bahan adalah modulus elastisitas, yang merupakan perbandingan dari tekanan yang diberikan dengan perubahan bentuk persatuan panjang, sebagai akibat dari tekanan yang diberikan. Besarnya nilai modulus elastisitas diperoleh dari persamaan 2 sebagai berikut.

Dimana :

$$
\mathrm{E}=\frac{f}{\epsilon}
$$

$\mathrm{E}=$ Modulus Elastisitas Beton Tekan (MPa)

$\mathrm{F}=$ Kuat Tarik Beton $(\mathrm{MPa})$

$\epsilon=$ Regangan $(\mathrm{mm})$

\section{METODE}

\section{Material}

Material utama pada textile reinforced concrete berupa komposit yang terdiri dari tekstil yang berfungsi sebagai reinforcement dan fine-grained concrete digunakan sebagai matriks. Bahan-bahan yang perlu dipersiapkan untuk matriks dalam penelitian antara lain.

Agregat halus yang digunakan adalah pasir yang memenuhi syarat lolos saringan 1,18 mm.

1) Semen dengan jenis Pozzolan Portland Cement (PPC).

2) Anyaman serat cantula, dengan variasi anyaman $10 \mathrm{~mm} \times 10 \mathrm{~mm}, 10 \mathrm{~mm} \times 15 \mathrm{~mm}, 10 \mathrm{~mm} \times 20 \mathrm{~mm}, 15 \mathrm{~mm}$ x $10 \mathrm{~mm}$ dan $20 \mathrm{~mm} \times 10 \mathrm{~mm}$.

3) Superplasticizer yang digunakan adalah SIKACIM® Superplasticizer yang diproduksi oleh PT. Sika Indonesia. Superplasticizer ini untuk meningkatkan flowability pada mortar.

4) Accelerator SIKACIM ${ }^{\circledR}$ Accelerator digunakan untuk membuat benda uji. Accelerator berguna untuk mempercepat pengerasan pada mortar dan meningkatkan kekuatan mortar pada umur awal.

5) Polymer Bonding Adhesive dari PT Ingus Badak. Polimer berguna sebagai perekat antara mortar dengan serat cantula.

\section{Benda Uji}

Benda uji yang digunakan pada penelitian ini berbentuk jam pasir dengan dimensi panjang $250 \mathrm{~mm}$, tebal $10 \mathrm{~mm}$ dan lebar $50 \mathrm{~mm}$. Pengujian benda uji dilakukan dengan cara tarik langsung pada umur 28 hari dengan menggunakan UTM. Reinforcement yang digunakan adalah anyaman serat cantula yang di tempelkan ke beton menggunakan Polymer Modified Mortar (PMM). Varisasi matriks yang diuji berupa anyaman serat cantula pada textile reinforced concrete (TRC). Variasi anyaman serat cantula yang akan diteliti yaitu $10 \mathrm{~mm} \times 10 \mathrm{~mm}, 10 \mathrm{~mm} \times 15 \mathrm{~mm}$, $10 \mathrm{~mm} \times 20 \mathrm{~mm}, 15 \mathrm{~mm} \times 10 \mathrm{~mm}$ dan $20 \mathrm{~mm} \times 10 \mathrm{~mm}$. Tiap variasi diatas dibuat masing masing 3 benda uji umur 28 hari, detail jumlah benda uji dapat dilihat pada Tabel 1 dibawah ini.

Tabel 1. Benda Uji Kuat Tarik PMM TRC

\begin{tabular}{cc}
\hline Kode & Jumlah \\
\hline TRC 000 & 3 \\
TRC 100 & 3 \\
TRC 150 & 3 \\
TRC 200 & 3 \\
TRC 051 & 3 \\
TRC 002 & 3 \\
\hline Jumlah & 18 \\
\hline
\end{tabular}

Pengujian kuat tarik ini dilakukan berdasarkan ASTM C-307-03 tetapi dengan modifikasi pada benda uji karena keterbatasan alat, alat yang dipakai adalah Universal Testing Machine (UTM). 


\section{Setting Test Speciment}

Benda uji yang telah dibuat selanjutnya akan diuji kuat tarik langsung hingga runtuh dengan menggunakan Universal Testing Machine (UTM).

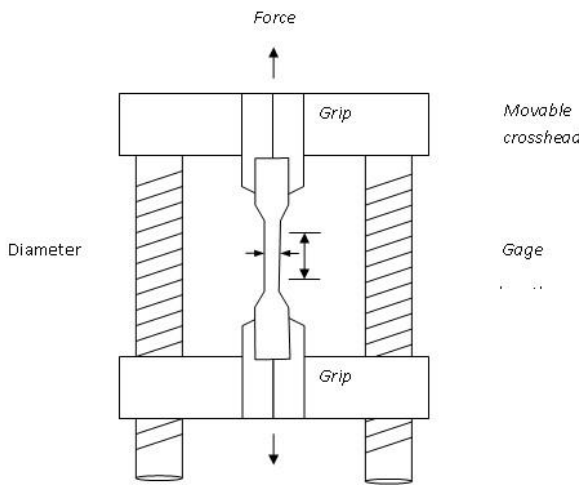

Gambar 2. Setting test speciment kuat tarik langsung

\section{HASIL DAN PEMBAHASAN}

\section{Hasil Uji Kuat Tarik}

Hasil uji kuat tarik menggunakan Polymer Modified Mortar (PMM) dengan bentuk jam pasir. Berikut adalah hasil uji kuat tarik pada Tabel 2

Tabel 2 Hasil Uji Kuat Tarik Langsung Polymer Modified Mortar berserat cantula

\begin{tabular}{cc}
\hline Kode & Kuat Tarik (Ff) (MPa) \\
\hline TRC 000 & 0.8 \\
TRC 100 & 1,0667 \\
TRC 150 & 1,2333 \\
TRC 200 & 1,5 \\
TRC 051 & 1,0 \\
TRC 002 & 0,9334 \\
\hline
\end{tabular}

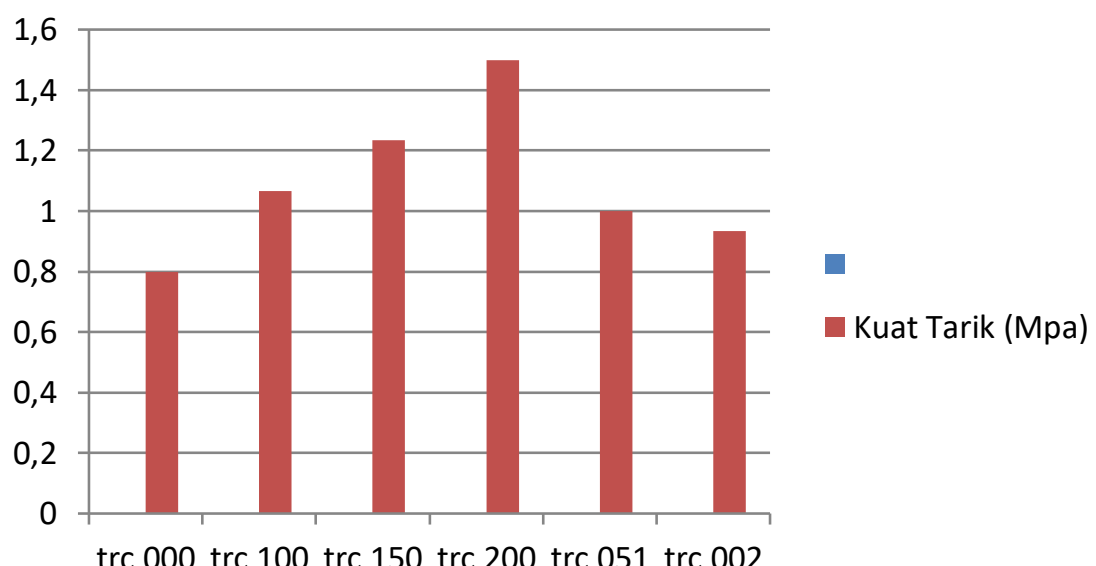

Gambar 3. Diagram Hubungan kuat tarik langsung PMM antar variasi anyaman serat cantula

\section{Perpanjangan Benda Uji}

Pengujian kuat tarik langsung dilakukan dengan variasi umur 28 hari menggunakan Universal Testing Machine (UTM) sehingga didapatkan beban tarik langsung maksimum (Pmaks) dan pertambahan panjang $(\Delta \mathrm{l})$.

Dari hasil uji tarik diatas didapatkan nilai perpanjangan benda uji. Berikut ini adalah nilai perpanjangan benda uji pada Tabel 3

Tabel 3 Nilai perpanjangan benda uji.

\begin{tabular}{ccc}
\hline Kode & $\begin{array}{c}\text { Kuat Tarik } \\
(\mathrm{MPa})\end{array}$ & $\begin{array}{c}\text { Pertambahan panjang } \\
(\Delta \mathrm{l})(\mathrm{mm})\end{array}$ \\
\hline TRC 000 & 0.8 & 1.87 \\
TRC 100 & 1,0667 & 1,8567 \\
TRC 150 & 1,2333 & 1,6934
\end{tabular}




\section{$\Delta \mathrm{I}(\mathrm{mm})$}

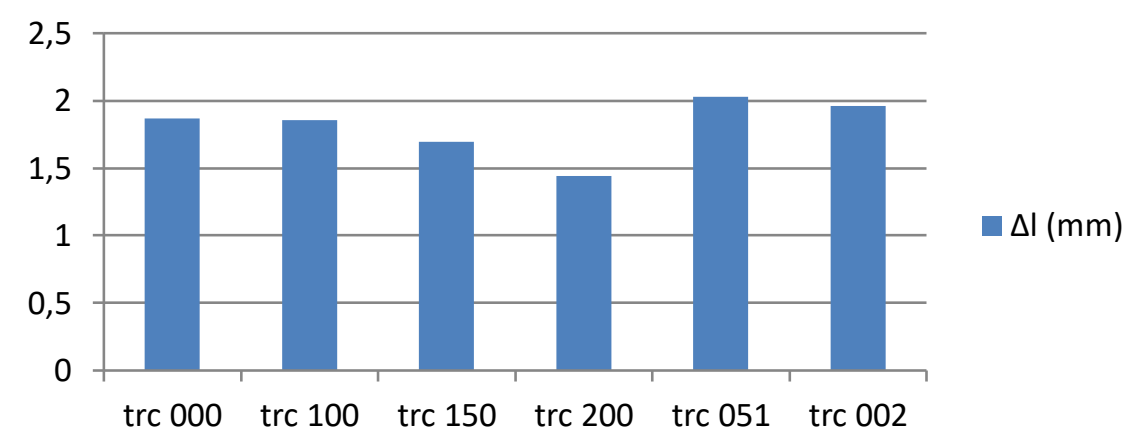

Gambar 4 Diagram Hubungan Perpanjangan Benda Uji antar Variasi Anyaman Serat Cantula

\section{Modulus Elastisitas}

Modulus elastisitas yang besar menunjukan beton mampu menahan beban yang besar dengan kondisi regangan yang kecil.

Hasil analisis modulus elastisitas pada Tabel 4 dibawah ini.

Tabel 4 Nilai Modulus Elastisitas

\begin{tabular}{cccc}
\hline KODE & $\begin{array}{c}\text { Kuat Tarik } \\
(\mathrm{MPa})\end{array}$ & $\begin{array}{c}\text { Pertambahan pan- } \\
\text { jang }(\Delta \mathrm{l})(\mathrm{mm})\end{array}$ & $\begin{array}{c}\text { Modulus }(\mathrm{E}) \\
(\mathrm{Mpa})\end{array}$ \\
\hline TRC 000 & 0.8 & 1.87 & 106.9572 \\
TRC 100 & 1,0667 & 1,8567 & 143.9205 \\
TRC 150 & 1,2333 & 1,6934 & 183.3984 \\
TRC 200 & 1,5 & 1,44 & 262.2968 \\
TRC 051 & 1,0 & 2,03 & 124.3722 \\
TRC 002 & 0,9334 & 1,96 & 119.4759 \\
\hline
\end{tabular}

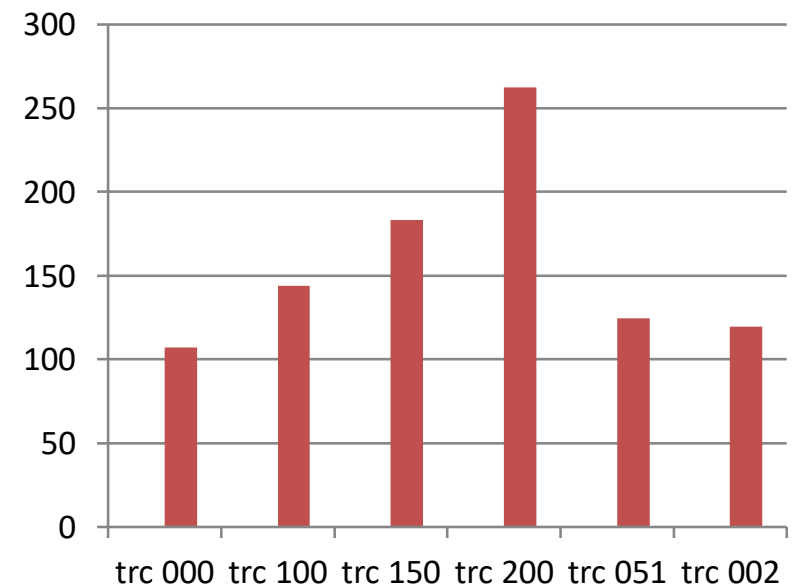

- Modulus

Elastisitas

(Mpa)

Gambar 5 Diagram Modulus Elastisitas PMM TRC dengan variasi anyaman serat cantula

\section{Rekapitulasi Analisis Perhitungan}

Setelah didapatkan hasil uji kuat tarik, pertambahan panjanng dan nilai modulus elastisitas PMM maka dapat dilihat pada tabel rekapitulasi sebagai berikut, 
Tabel 5 Rekapitulasi Kuat Tarik, Pertambahan Panjang Benda Uji dan Moudulus Elastisitas

\begin{tabular}{cccc}
\hline KODE & $\begin{array}{c}\text { Kuat Tarik } \\
(\mathrm{MPa})\end{array}$ & $\begin{array}{c}\text { Pertambahan pan- } \\
\text { jang }(\Delta \mathrm{l})(\mathrm{mm})\end{array}$ & $\begin{array}{c}\text { Modulus }(\mathrm{E}) \\
(\mathrm{MPa})\end{array}$ \\
\hline TRC 000 & 0.8 & 1.87 & 106.9572 \\
TRC 100 & 1,0667 & 1,8567 & 143.9205 \\
TRC 150 & 1,2333 & 1,6934 & 183.3984 \\
TRC 200 & 1,5 & 1,44 & 262.2968 \\
TRC 051 & 1,0 & 2,03 & 124.3722 \\
TRC 002 & 0,9334 & 1,96 & 119.4759 \\
\hline
\end{tabular}

\section{KESIMPULAN}

Berdasarkan hasil pengujian didapatkan nilai kuat tarik dan nilai modulus elastisitas pada Polymer Modified Mortar (PMM) dengan penambahan variasi anyaman serat cantula dapat disimpulkan :

1) Nilai kuat tarik optimum terjadi pada variasi anyaman serat cantula $10 \mathrm{~mm} \times 20 \mathrm{~mm}$ (TRC 200) sebesar 1,5 MPa atau 87,5\% lebih tinggi jika dibandingkan dengan PPM tanpa penambahan anyaman serat cantula.

2) Nilai pertambahan panjang optimum terjadi pada variasi anyaman serat $15 \mathrm{~mm} \times 10 \mathrm{~mm}$ (TRC 051) yaitu sebesar 2,03 $\mathrm{mm}$ atau 8,5562\% lebih tinggi jika dibandingkan dengan PMM tanpa penambahan anyaman serat cantula.

3) Nilai Modulus Elastisitas optimum terjadi pada variasi anyaman serat cantula $10 \mathrm{~mm} \times 20 \mathrm{~mm}$ (TRC 200) sebesar 262,2968 MPa atau 145,2352 \% lebih tinggi jika dibandingkan dengan PMM tanpa penambahan anyaman serat cantula.

\section{REFERENSI}

EFNARC. 2002. Specification and Guidelines For Self-Compacting Concrete. EFNARC Association House, UK.

Triantafillou, P.E. 2007. Textile-Reinforced Mortar (TRM) versus FRP Confinement in Reinforced Concrete Columns. ACI Structural Journal.

ASTM C-109. 2016. Standart Test Methode for Compressive Strength of Hydraulic Cement Mortars (Using 2-in. Or [50-mm] Cube Specimen). Annual Books of ASTM Standart USA.

Ohama, Yoshihiko. 1995. Handbook of Polymer-Modified Concrete and Mortars Properties and Pricess Technology. USA : Noyes Publications.

ASTM C-579-01. 2012. Standart Test Methode for Compressive Strength of Chemical Resistance Mortar, Grout, Monolithic Surfacings and Polymer Concrete. Annual Books of ASTM Standart USA.

Raharjo, Wijang W. 2015 Sifat tarik dan Lentur Komposit rHDPE / Serat Cantula dengan Variasi panjang Serat. Surakarta : Universitas Sebelas Maret

Kartika, Febiana Yoda.2018. Pengaruh Volume Fraction dan Aspek Rasio Serat Agave Cantula Roxb Dengan Polymer Modified Mortar Terhadap Kuat Tekan dan Kuat Tarik Langsung. Surakarta: Universitas Sebelas Maret Surakarta. 